\title{
Improvement of curd mass production technology
}

\author{
Yuri Gerber ${ }^{1,}$, Ekaterina Oshchepkova ${ }^{1}$, Alexander Gavrilov ${ }^{1}$, and Dmitry Ermolin ${ }^{1}$ \\ ${ }^{1}$ Agrotechnological Academy, V. I. Vernadsky Crimean Federal University, Simferopol, the Republic \\ of Crimea, Russian Federation
}

\begin{abstract}
The article is devoted to the improvement of the curd mass production technology developed by the authors earlier, in particular, the selection of the fruit component to be added to the product to improve its nutritional qualities. Besides, the organoleptic and physicochemical characteristics of the proposed product have been evaluated and its fatty acid composition has been analyzed in order to confirm the beneficial properties of the curd under consideration. The relevance and novelty of the topic lies in the use of a fruit component that has not been previously used in such technologies, as well as in the creation of the product having a balanced content of nutrients, vitamins, and antioxidants.
\end{abstract}

\section{Introduction}

Differentiation of dairy products for various groups of the population, taking into account the creation of new types of functional and healthy diets, has led to the search for new recipes, which would take into consideration regional specifics. So, at present, the emphasis is on low-fat dairy products with the addition of natural fruit components that contain a sufficient amount of vitamins and antioxidants. Choosing the fruit component to be introduced into the product, we considered, first of all, fruit, grown on the territory of the Republic of Crimea and providing balanced nutrition to the local population and a large number of visitors.

Lots of fruits with qualitative organoleptic characteristics, as well as useful properties, ripen on the territory of the Crimean Peninsula from May to October.

The purpose of the study is to improve the production technology of curd mass with the addition of grape seed oil and fruit component

The objectives of the study.

1. Selection of the component to be added.

2. Development of the production technology of curd mass with the addition of grape seed oil and fruit component.

3. Assessment of organoleptic parameters.

4. Assessment of physical and chemical parameters.

5. Analysis of the fatty acid composition of the obtained curd mass by gas chromatography.

6. Formulation of conclusions.

\footnotetext{
* Corresponding author: gerber_1961@mail.ru
} 


\section{Selecting the component to be added}

Previously, we have already conducted research on obtaining curd mass with the addition of grape seed oil and achieved good results [1]. Analyzing the raw material base of the Crimea, we came across a large number of fruits that can be used in the production of curd mass. The purpose of the selection of the added component is to achieve a synergistic effect. Thus, the fruit culture of ziziphus has been chosen, which has good medicinal properties, in particular, it stabilizes the blood pressure [2]. In combination, grape seed oil and ziziphus fruits enhance each other's actions due to the large amount of macronutrients, fatty acids and vitamins contained in their composition.

The addition of grape seed oil enriches the product with a large amount of tannins, antioxidants, and vitamins; most importantly, omega-3 and omega- 6 fatty acids enter the product in large quantities. In addition to grape seed oil, dried ziziphus is introduced into the curd mass, the fruits of which contain up to $10 \%$ tannins, flavone glycosides and flavonoids, resins, coumarins, up to $2.5 \%$ organic acids, among which malic, tartaric and succinic acids prevail; dried ziziphus also contains folic and ziziphus acids, and is characterized by a high carbohydrate content.

Pharmacological and clinical studies have confirmed the diuretic properties of fruits and leaves of ziziphus, namely, balancing the ratio between the intake and excretion of fluid from the human body. According to clinical observations, the fruits also exhibit anti-hypertensive properties.

Vitamin $\mathrm{C}$ percentage in the vitamin and mineral composition of zizyphus is the greatest; however, vitamins B1, B2, B5, K, P-active compounds, carotenoids, potassium, calcium, phosphorus, magnesium and iron are also present in sufficient amounts [2].

Table 1. Chemical composition of raw ziziphus (in $100 \mathrm{~g}$ of the product).

\begin{tabular}{|c|c|}
\hline Property, substance & Value \\
\hline Calorie content, $\mathrm{kcal}$ & 79 \\
\hline Protein content, $\mathrm{g}$ & 1.2 \\
\hline Carbohydrate content, $\mathrm{g}$ & 20.2 \\
\hline Fat content, $\mathrm{g}$ & 0.2 \\
\hline Micro- and macro elements & 0.51 \\
\hline Ash, g & 77.8 \\
\hline Water, g & 3 \\
\hline Sodium, mg & 250 \\
\hline Potassium, mg & 23 \\
\hline Phosphorus, mg & 10 \\
\hline Magnesium, mg & 21 \\
\hline Calcium, mg & 0.07 \\
\hline Copper, mcg & 0.08 \\
\hline Manganese, mg & 0.05 \\
\hline Zinc, $\mathrm{mg}$ & 0.48 \\
\hline Iron, $\mathrm{mg}$ &
\end{tabular}


Table 2. Chemical composition of dried ziziphus (moisture content 22\%; in $100 \mathrm{~g}$ of the product).

\begin{tabular}{|c|c|}
\hline Property, substance & Value \\
\hline Calorie content, $\mathrm{kcal}$ & 287 \\
\hline Protein content, $\mathrm{g}$ & 3.7 \\
\hline Carbohydrate content, $\mathrm{g}$ & 73.6 \\
\hline Fat content, $\mathrm{g}$ & 1.1 \\
\hline Micro- and macro elements & 1.9 \\
\hline Ash, g & 19.7 \\
\hline Water, g & 9 \\
\hline Sodium, mg & 531 \\
\hline Potassium, mg & 100 \\
\hline Phosphorus, mg & 37 \\
\hline Magnesium, mg & 79 \\
\hline Calcium, mg & 0.27 \\
\hline Copper, mcg & 0.31 \\
\hline Manganese, mg & 0.19 \\
\hline Zinc, mg & 1.8 \\
\hline Iron, mg & \\
\hline
\end{tabular}

Based on the available data on the chemical composition of raw and dried ziziphus, dried ziziphus has been chosen to be used in further research, since it is better stored, has an increased content of macro- and microelements, vitamins and other useful substances.

\section{Development of production technology of curd mass with the addition of grape seed oil and fruit component}

The production technology of curd mass includes the preparation of a mixture containing a milk base and a vegetable filler, followed by heat treatment, aging, packaging and cooling of the finished product. The milk is pre-normalized to a $1-2 \%$ fat content (depending on the protein content in the milk raw material), pasteurized, cooled to the fermentation temperature. Then lyophilized starter culture made of a mixture of lactococci and streptococcus, calcium chloride and milk-clotting enzyme is added. The fermentation having finished, the resulting curd is pressed to achieve a desirable range of moisture content. Glucose-fructose curd syrup is added to the resulting cottage cheese and mixed; then grape seed oil is added and the resulting mixture is sent to a rolling apparatus to distribute the oil equally throughout the mass. Pieces of cut ziziphus preliminarily dried to $20-25 \%$ moisture content are added to the resulting curd mass and mixed thoroughly. The resulting prepared curd mass is sent to be packed at a temperature of $4-6{ }^{\circ} \mathrm{C}$. 


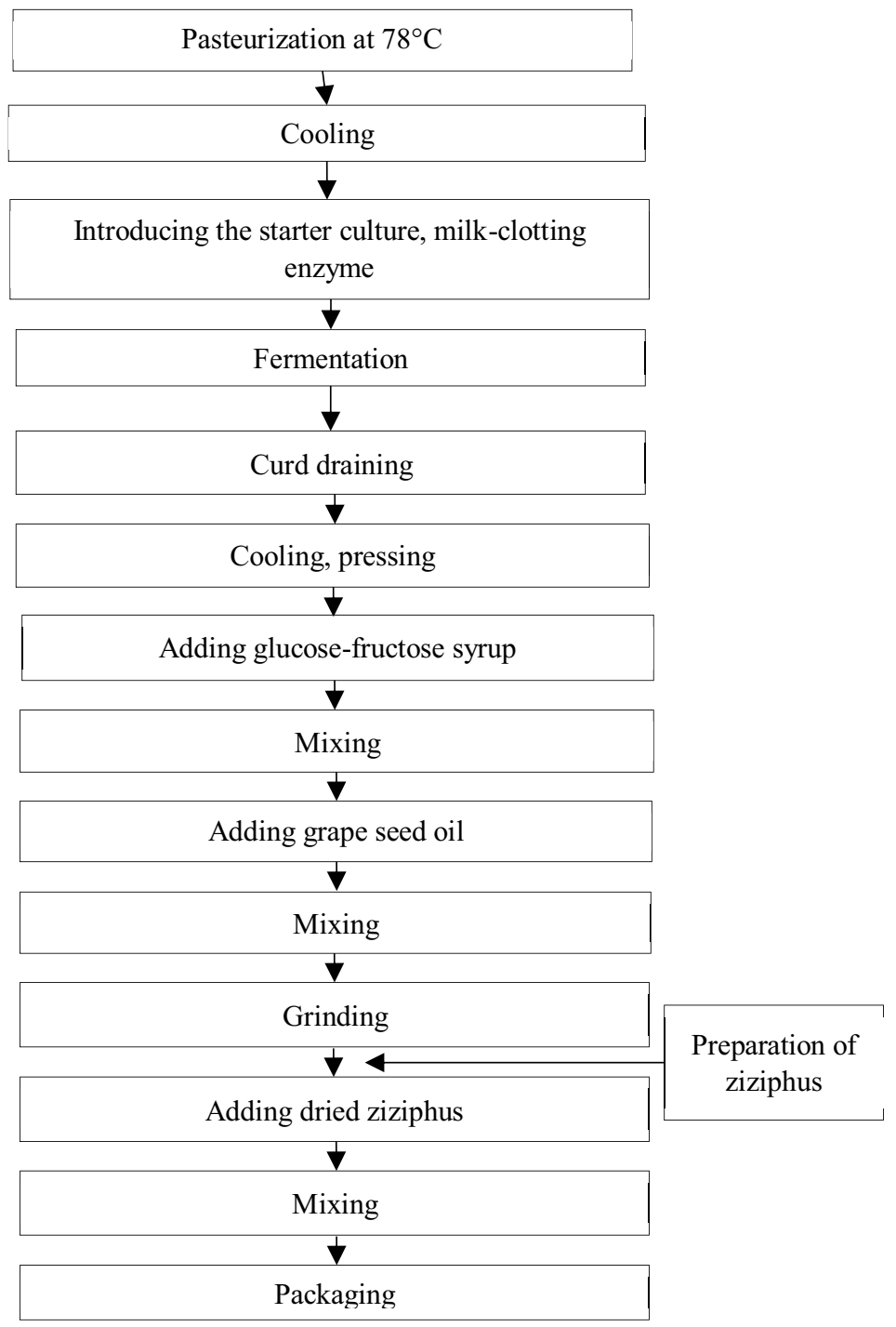

Fig. 1.The Flow Diagram for Production.

\section{Analysis of the results achieved}

Table 3 presents organoleptic parameters of the curd mass of the proposed composition.

Table 3. The Organoleptic Parameters of Prepared Curd Mass.

\begin{tabular}{|c|c|}
\hline Taste and smell & $\begin{array}{c}\text { Pure, sour-milk, without foreign flavors and odors, with an } \\
\text { aftertaste characteristic of grape seed oil and pronounced flavor } \\
\text { of ziziphus }\end{array}$ \\
\hline Color & $\begin{array}{c}\text { White homogenous. A slightly greenish tint is acceptable } \\
\text { due to the grape seed oil present. }\end{array}$ \\
\hline Consistency & $\begin{array}{c}\text { Soft, smearing consistency with perceivable particles of } \\
\text { milk protein and pieces of dried ziziphus. }\end{array}$ \\
\hline
\end{tabular}


Analyzing the data obtained, it can be concluded that the curd mass under consideration has satisfactory organoleptic characteristics; the use of the mentioned components does not cause deviations of the parameters from the requirements of the standard.

Table 4. The physical and chemical indicators of the curd mass.

\begin{tabular}{|c|c|}
\hline Parameter & Value \\
\hline Acidity, ${ }^{\circ} \mathrm{T}$ & 160 \\
\hline Fat content, $\%$ & 7 \\
\hline Moisture content, $\%$ & 75 \\
\hline Phosphatase or peroxidase & Not detected \\
\hline Temperature & $4 \pm 2$ \\
\hline
\end{tabular}

Analyzing the obtained physical and chemical characteristics, it can be concluded that the curd mass corresponds to the parameters of the current State Standard (GOST).

\subsection{Analysis of fatty acid composition}

The fatty acid composition of cottage cheese with $5 \%$ fat content and the proposed curd mass with grape seed oil and ziziphus was determined by gas chromatography in a certified laboratory diagnostic center of the branch of the Federal Center for Animal Health in the Republic of Crimea.

Table 5. Comparative data on fatty acid composition of cottage cheese with $5 \%$ fat content and the proposed curd mass.

\begin{tabular}{|c|c|c|}
\hline Component & $\begin{array}{l}\text { The percentage of fatty } \\
\text { acids in the curd mass } \\
\text { of the proposed } \\
\text { composition }\end{array}$ & $\begin{array}{l}\text { The percentage of fatty } \\
\text { acids in cottage cheese } \\
\text { with } 5 \% \text { fat content }\end{array}$ \\
\hline C:6 Caproic (Hexanoic) acid & 2.816 & 37.482 \\
\hline C:14 Myristic (tetradecanoic) acid & 1.801 & - \\
\hline C:16 Palmitic (Hexadecanoic) acid & 11.868 & 50.388 \\
\hline C:18:0 Stearic (Octadecanoic) & 1.707 & - \\
\hline $\begin{array}{l}\text { C:18:1n9c Oleic (cis-9- } \\
\text { Octadecenoic) acid }\end{array}$ & 5.267 & 4.617 \\
\hline $\begin{array}{l}\text { C 22:1n9 Erucic (cis-13 } \\
\text { Docosenoic) acid }\end{array}$ & 3.011 & - \\
\hline $\begin{array}{l}\text { C 20:3n3 Eicosatrienoic (Cis- } \\
\text { 11,14,17-Eicosatrienoic) acid }\end{array}$ & 0.368 & - \\
\hline $\begin{array}{c}\text { C 20:4n6 Arachidonic (cis- } \\
5,8,11,14 \text {-Eicosatetraenoic) acid }\end{array}$ & 2.054 & - \\
\hline $\begin{array}{l}\text { C 20:5n3 Eicosapentaenoic (cis- } \\
\text { 5,8,11,14,17-Eicosapentaenoic) } \\
\text { acid }\end{array}$ & 67.979 & - \\
\hline $\begin{array}{c}\text { С 22:6 Окозагексаеновая } \\
\text { Docosahexaenoic (cis- } \\
4,7,10,13,16,19 \text {-Docosahexaenoic) } \\
\text { acid }\end{array}$ & 3.130 & - \\
\hline $\begin{array}{c}\mathrm{C}: 18: \ln 9 \mathrm{t} \text { Elaidic } \\
\text { (trans-9-Octadecenoic) acid }\end{array}$ & - & 3.406 \\
\hline C 22:2 Docosadienoic acid & - & 4.107 \\
\hline Total & 100 & 100 \\
\hline
\end{tabular}




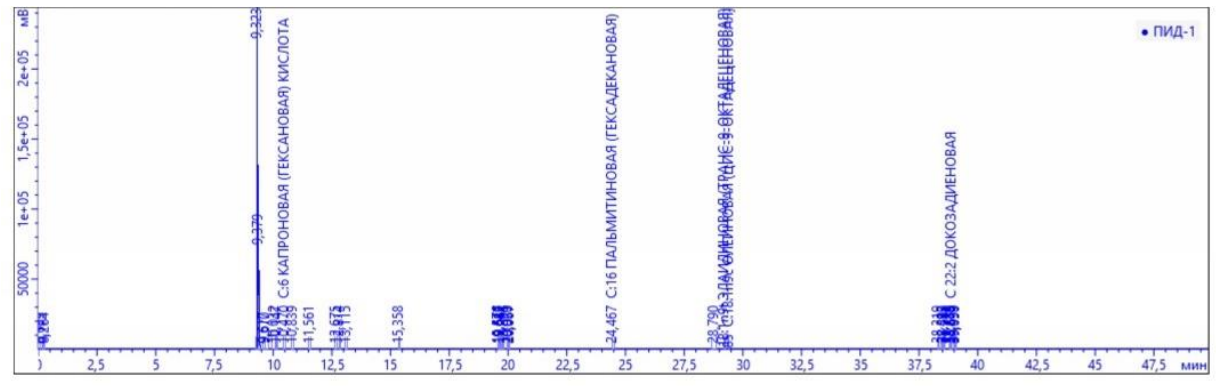

Fig. 2. Chromatogram of the fatty acid composition in cottage cheese with $5 \%$ fat content.

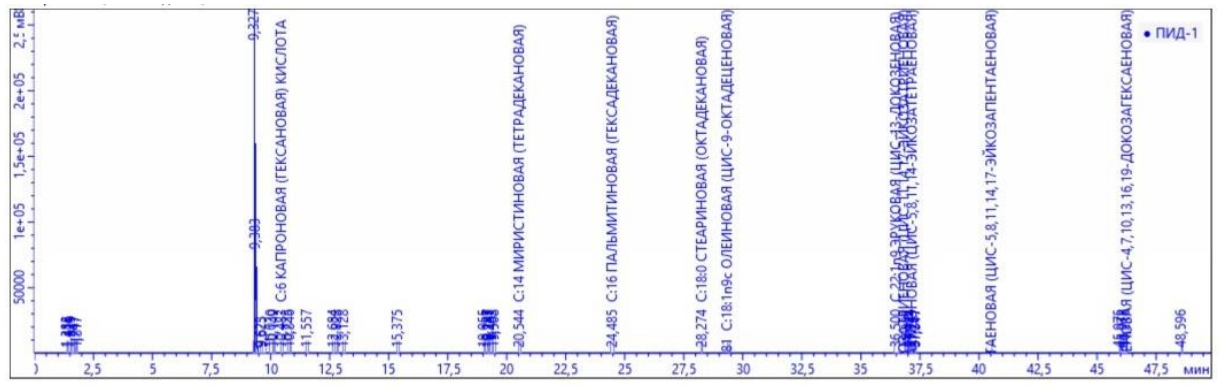

Fig. 3. Chromatogram of the fatty acid composition in the curd mass with grade seed oil and ziziphus.

The Fatty Acid Composition in Cottage Cheese with 5\% Fat Content, $\%$

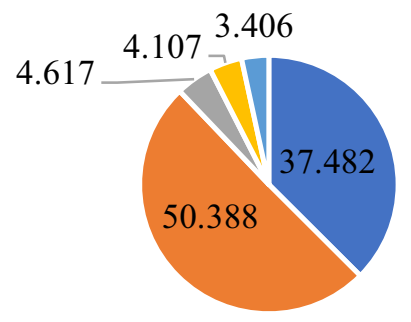

- C:6 Caproic (Hexanoic) acid

- C:16 Palmitic (Hexadecanoic)

- C:18:1n9c Oleic (cis-9-Octadecenoic)

- $22: 2$ Docosadienoic

- C:18:1n9t Elaidic (trans-9-Octadenecoic)

Fig. 4. Diagram of the fatty acid composition in cottage cheese with $5 \%$ fat content. 
The Fatty Acid Composition in the Curd Mass with Grade

Seed Oil and Ziziphus, \%

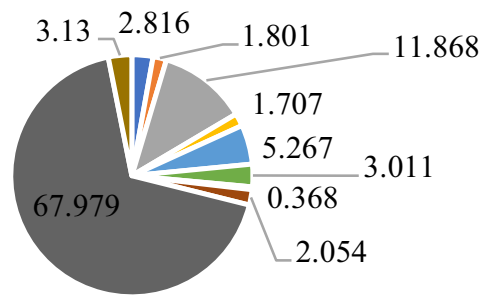

- C:6 Caproic (Hexanoic) acid

- C:14 Myristic (tetradecanoic)

- C:16 Palmitic (Hexadecanoic)

¿ C:18:0 Stearic (Octadecanoic)

- C:18:1n9c Oleic (cis-9-Octadecenoic)

- C 22:1n9 Erucic (cis-13 Docosenoic)

- C 20:3n3 Eicosatrienoic (Cis-11,14,17-Eicosatrienoic)

- C 20:4n6 Arachidonic (cis-5,8,11,14-Eicosatetraenoic)

- C 20:5n3 Eicosapentaenoic (cis-5,8,11,14,17-Eicosapentaenoic)

Fig. 5. Diagram of the fatty acid composition in the curd mass with grade seed oil and ziziphus, $\%$.

Analyzing the data obtained, we can conclude that the curd mass with the added grape seed oil and ziziphus is enriched with useful and necessary Omega- 3 and Omega- 6 fatty acids, namely, C 20:4n6 Arachidonic (cis-5,8,11,14-Eicosatetraenoic), C 20:3n3 Eicosatrienoic (Cis-11,14,17-Eicosatrienoic), Docosahexaenoic (cis-4,7,10,13,16,19Docosahexaenoic) acids.

Omega-3 and omega- 6 polyunsaturated fatty acids contained in the composition of the proposed curd mass have a positive effect on the nervous system, as well as regulate redox reactions in the cells of the body. From all of the above, it follows that omega- 3 and omega6 fatty acids contained in the resulting curd mass improve the functioning of all organs and systems of the body.

Eicosanoids formed from these fatty acids contribute to the regulation of blood pressure, normalize the rheological properties of blood, and accelerate tissue repair due to the formation of leukotrienes.

\section{Conclusion}

In the course of the study, the intended goal has been achieved, all the tasks having been completed. The component to be added has been selected. The technology for the production of curd mass with grape seed oil and dried ziziphus has been developed. Organoleptic and physicochemical analysis of the resulting product has been conducted. The indisputable advantage of curd mass with added grape seed oil and dried ziziphus was proved through analysis of the fatty acid composition by gas chromatography. 
Further research will be aimed at substantiating the optimal parameters of the proposed technology and energy-saving technical means for its implementation.

\section{References}

1. Y.B. Gerber, A.V. Gavrilov, V.I. Omelchuk, E.V. Oshchepkova, E3S Web of Conferences 175, 8 (2020)

2. Yu.B. Gerber, A.V. Gavrilov, N.S. Kiyan, Bulletin of agricultural science of Tavrida 8(171), 55-62 (2016)

3. Y.B. Gerber, A.V. Gavrilov, Technique and technology of food production 3 (2019)

4. O.V. Kozlova T.Ch. Tultabaeva, Proceedings of the International Symposium (FSBEI HE "Kemerovo State University", Kemerovo, 2018)

5. O.V. Krieger, Xu Wei, Proceedings of the International Symposium (FSBEI HE "Kemerovo State University",Kemerovo, 2018)

6. O.V. Kriger, S.Yu. Noskova, Technique and technology of food production 4, 30-38 (2018)

7. V.I. Dorovskikh, D.V. Dorovskikh, S. Allami, Science in Central RUSSIA Tambov 5(23), 62-69 (2016)

8. O.N. Musina, M.P. Shchetinin, Food industry (2017)

9. L.A. Bobrakova, A.V. Mamaev, Bulletin of Agrarian Science (2013)

10. O.V. Penzina, O.V. Pasko, Food industry (2013)

11. L.G. Germanskaya, O.V. Pasko, O.V. Penzina, Agrarian Bulletin of the Urals (2014)

12. D.L. Klabukova, S.E. Strogov, V.V. Turkin, N.G. Mashentseva, Food Industry (2013)

13. L.G. Germanic, O.V. Penzina, O.V. Pasko, Food Industry (2014)

14. I.D. Karomatov, A.T. Abduvokhidov, Biology and integrative medicine (2018)

15. L.A. Zabodalova, M.S. Solovieva, Scientific journal of NRU ITMO. Series "Processes and Apparatus for Food Production" (2014)

16. M.A. Kharchenko, Correlation analysis (Voronezh State University Publishing and Printing Center, 2008)

17. D.V. Klyuchnikova, A.A. Kuznetsova, A.V. Krikunov, Bulletin of the South Ural State University. Series: Food and Biotechnology (2017)

18. Y.B. Gerber, A.V. Gavrilov, S.V. Chunikhin, D.V. Ermolin, Machines and equipment for processing agricultural products (Publishing house Polyprint LLC, 2020)

19. I.E. Akopov, The most important domestic medicinal plants and their use (Tashkent, Medicine, 1990)

20. Leo Nollet, Toldra Fidel, Handbook of Dairy foods analysis (CRC Press, 2010)

21. Ramesh C. Chandan, Arun Kilara, Nagendra P. Shah, Dairy processing \& Quality Assurance (Wiley Blackwell, 2008)

22. Young W. Park, Bioactive components in Milk \& Dairy Products (Wiley Blackwell, 2009)

23. T.J. Britz, K. Richard, Advanced Dairy science \& Technology (Blackwell Publishing, 2008)

24. P.M. McSweeney, P.F. Fox, J.W. Fuquay, Encyclopedia of Dairy Sciences (Elsevier Science, 2011) 